\title{
SEMENTE de Araucaria Angustifolia: ASPECTOS MORFOLÓGICOS E COMPOSIÇÃO QUÍMICA DA FARINHA
}

\author{
ADRIANA CAMPOS DE VASCONCELLOS CAPELLA* \\ PATRICIATEIXEIRAPADILHADA SILVA PENTEADO** \\ MARIA EUGENIA BALB|***
}

\begin{abstract}
Sementes de Araucaria angustifolia cruas e cozidas foram submetidas à secagem por circulação de ar a $65^{\circ} \mathrm{C}$ e moídas como farinhas. Efetuaram-se análises da composição centesimal das sementes e farinhas e de morfologia por microscopia eletrônica de varredura (microscópio Jeol JSM 6360LV). As farinhas obtidas são boas fontes de fibras $(5,11 \%$ para COZF65 e $6,45 \%$ para CRF65), proteínas (3,41\% para COZF65 e 3,07\% para CRF65) e lipídios (5,14\% para COZF65 e 6,39\% para CRF65). Os resultados mostraram que a farinha de pinhão cozido apresentou maiores alterações decorrentes dos tratamentos de cocção, moagem e secagem. Sob os aspectos químico e nutricional, as farinhas constituem opção tecnológica para o processamento das sementes da Araucaria angustifolia.
\end{abstract}

PALAVRAS-CHAVES: Araucaria angustifolia; SECAGEM; DESIDRATAÇÃO.

* Química, Mestranda em Tecnologia de Alimentos, Universidade Federal do Paraná (UFPR), Curitiba, PR (e-mail: acapella@ufpr.br).

** Professora, Doutora em Meio Ambiente e Desenvolvimento, UFPR, Curitiba, PR (e-mail: ppenteado@ufpr.br).

*** Professora, Mestre em Ciência dos Alimentos, UFPR, Curitiba, PR (e-mail: eugeniab@ufpr.br). 


\section{INTRODUÇÃO}

As vantagens da utilização de técnicas de conservação de produtos como, por exemplo, os processos de secagem estão relacionadas com a redução do seu peso e volume, dos custos de transporte e armazenamento, bem como o aumento da vida-de-prateleira dos alimentos (PARK, YADO e BROD, 2001).

A maioria das sementes quando secas pode ser mantida armazenada durante longo período de tempo, bem como tolerar processo de secagem até abaixo de $10 \%$ de umidade sem perder a viabilidade de germinação, sendo chamadas de sementes ortodoxas. Por outro lado, as sementes recalcitrantes resistem a esse tipo de tratamento devido a sua alta suscetibilidade à perda de água. $O$ armazenamento de sementes com alto grau de umidade favorece a germinação e o ataque de microorganismos (NEVES, 1994). Exemplos desse tipo de sementes estão relacionados à importância industrial (seringueira, cacaueiro), florestal (araucária, andiroba, ingá) e frutíferas (abacateiro, mangueira, jaqueira, citros) que são disseminadas em solos com teores elevados de umidade, em meios úmidos ou durante a estação chuvosa (FONSECA e FREIRE, 2003).

AAraucaria angustifolia (Bertol.) Kuntze, espécie encontrada na América do Sul, está inserida no domínio da Mata Atlântica e nomeada Floresta Ombrófila Mista pelo encontro das floras Temperada Austro-brasileira e Tropical Afro-brasileira, sendo também conhecida como floresta de pinheiros, pinhais ou mata de araucária. Suas sementes, conhecidas como pinhões, apresentam casca de cor marrom avermelhada. A polpa, parte comestível e muito dura quando crua, necessita de processo de abrandamento de sua textura para permitir o consumo. Seu desenvolvimento ocorre em locais de grandes altitudes, entre 500 e $1500 \mathrm{~m}$, com temperatura anual média entre 11,5 e $21^{\circ} \mathrm{C}(\mathrm{KOCH}$ e CORREIA, 2002).

Pesquisas científicas têm contribuído para o desenvolvimento de novas tecnologias, produtos e ingredientes na indústria de alimentos de maneira a gerar grande variedade e aplicação de produtos como as sopas instantâneas com vegetais desidratados, sucos de frutas em pó e frutas desidratadas como maçã, abacaxi, manga, banana e tomate seco (SBRT, 2007).

CLADERA-OLIVERA (2005) estudaram as melhores condições de processamento e armazenamento e a possibilidade de elaboração de novos produtos à base de pinhão, tais como misturas para sopa, suflê, bolos e biscoitos. O uso culinário da farinha de pinhão também foi pesquisado por LIMA (2006), incluindo a caracterização físico-química da semente e o isolamento do amido.

O objetivo deste trabalho foi caracterizar a composição química da farinha de pinhão, relacionada às condições de pré-tratamento e desidratação, como opção tecnológica na utilização nutricional de produtos alimentícios.

\section{MATERIAL E MÉTODOS}

\subsection{AMOSTRAS}

Sementes da Araucaria angustifolia, recém-colhidas no período de junho de 2007, provenientes da Região Metropolitana de Curitiba (Paraná) foram amostradas para o presente estudo.

\subsection{PROCESSAMENTO DAS SEMENTES}

O pinhão fresco com casca foi cozido em tacho aberto com água fervente por 30 minutos, conforme descrito por CORDENUNSI et al. (2004). Pinhões crus e cozidos foram descascados manualmente e picados com o auxílio de faca (pedaços de cerca de $0,5 \mathrm{~cm}$ ), e separados para constituírem as amostras das matérias-primas de semente fresca crua e de semente cozida. 
A secagem de parte das amostras foi realizada em estufa com circulação forçada de ar (Nova Ética, modelo 400/2ND) em temperatura de $65^{\circ} \mathrm{C}$ até alcançar umidade inferior a 15\% (BRASIL, 2005). As amostras foram trituradas em moinho laboratorial Wiley, na condição em que $95 \%$ do produto passasse pela peneira com abertura de malha de $250 \mu \mathrm{m}$. As farinhas e as sementes de pinhão cru e cozido foram embaladas em plásticos de poli (cloreto) de vinila (PVC) e mantidas em refrigerador.

As amostras de semente de pinhão e as duas farinhas foram classificadas, segundo o tratamento submetido em: semente fresca crua (CRF) e semente cozida (COZF), farinha crua desidratada a $65^{\circ} \mathrm{C}$ (CRF65) e farinha cozida desidratada a $65^{\circ} \mathrm{C}$ (COZF65).

\subsection{ANÁLISES}

As amostras de semente crua (ou in natura) e cozida, e suas respectivas farinhas, foram submetidas às análises de umidade (método 925.10 da AOAC, 2000); resíduo mineral fixo (método 900.02 da AOAC, 2000); proteínas pelo método de Kjeldahl (FAO, 1973 apud GREENFIELD e SOUTHGATE, 1992), utilizando-se o fator 6,25 para conversão do nitrogênio; lipídios (método $900.2 \mathrm{~A}$ da AOAC, 2000) e fibra alimentar pela combinação de métodos enzimáticos e gravimétricos (método 992.16 da AOAC, 2000). Os carboidratos disponíveis foram calculados por diferença (IAL, 1985). As amostras de farinha foram metalizadas em equipamento Balzers Union, modelo SCD 030, e observadas no microscópio eletrônico de varredura Jeol JSM 6360LV com capacidade de zoom de 8000 x.

\subsection{DELINEAMENTO ESTATÍSTICO}

Os dados obtidos foram submetidos ao programa Microsoft Office Excel (MICROSOFT, 2003) para o cálculo das médias, desvio-padrão e coeficiente de variação. De acordo com KOELLER (1999) foi utilizado o programa MSTAT-C para os testes de Anova, Tukey e Factor para verificação da análise de variância, existência de diferenças estatísticas entre as médias e covariância (nível de significância a 5\%).

\section{RESULTADOS E DISCUSSÃO}

Tratando-se de semente recalcitrante, somente a secagem não seria o suficiente para armazenála de forma a não comprometer sua viabilidade. A opção de transformá-la em farinha constitui alternativa para sua conservação, considerando a sazonalidade de produção do pinhão.

As secagens industriais de grãos de trigo (Triticum aestivum L.) ocorrem mediante a entrada de ar aquecido a $70^{\circ} \mathrm{C}$ nos secadores e alcance de temperaturas de $40-60^{\circ} \mathrm{C}$ na massa dos grãos. No caso dos grãos de cevada (Hordeum vulgare) são utilizadas temperaturas de $65^{\circ} \mathrm{C}$ do ar de secagem para alcançar $45^{\circ} \mathrm{C}$ na massa e não causar danos estruturais às sementes (AGROLINK, 2007).

O tempo de secagem a $65^{\circ} \mathrm{C}$ para o pinhão, segundo os padrões de umidade preconizados pela ANVISA (BRASIL, 2005), foi de aproximadamente cinco horas e atingiu valores de $12,25 \%$ para CRF e $13,32 \%$ para COZF.

\subsection{COMPOSIÇÃO CENTESIMAL DAS SEMENTES E DAS FARINHAS DE PINHÃO DE Araucaria angustifolia}

Os teores de proteínas, lipídios e carboidratos no pinhão CRF (matéria-prima) podem variar de acordo com o estágio de desenvolvimento das sementes da Araucaria angustifolia (FERNANDEZ, 2003). Tais variações estão relacionadas com a desidratação nas etapas finais de maturação, que pode alterar o teor de proteínas em até 15\% e fatores como a composição do solo e o clima.

A Tabela 1 mostra a composição centesimal das sementes de pinhão CRF e COZF e de suas farinhas obtidas pelo processo de secagem por circulação de ar. 


\section{TABELA 1 - COMPOSIÇÃO CENTESIMAL (g/100 g) DAS SEMENTES DE Araucaria angustifolia}

E FARINHAS DE PINHÕES SUBMETIDAS À SECAGEM A $65^{\circ} \mathrm{C}$

\begin{tabular}{|c|c|c|c|c|c|c|}
\hline \multirow{2}{*}{ Tratamento $^{(2)}$} & \multicolumn{6}{|c|}{ COMPOSIÇÃO CENTESIMAL (g/100 g) EM BASE SECA ${ }^{(1)}$} \\
\hline & UMIDADE & PROTEÍNAS * & LIPÍDIOS * & CINZAS * & \begin{tabular}{|c|} 
FIBRA \\
ALIMENTAR* \\
\end{tabular} & CARBOIDRATO* \\
\hline CRF & $51,16 \pm 0,29 \mathrm{~A}$ & $6,59 \pm 0,15 \mathrm{~A}$ & $7,38 \pm 0,31 \mathrm{AB}$ & $2,85 \pm 0,36 \mathrm{~A}$ & $15,34 \pm 0,25 B$ & $67,84 \mathrm{C}$ \\
\hline COZF & $49,70 \pm 0,25 B$ & $6,31 \pm 0,15 \mathrm{~A}$ & $6,27 \pm 0,31 \mathrm{~B}$ & $3,57 \pm 0,68 \mathrm{~A}$ & $16,88 \pm 0,23 \mathrm{~A}$ & $66,96 \mathrm{C}$ \\
\hline CRF65 & $8,29 \pm 0,29 \mathrm{D}$ & $3,07 \pm 0,06 \mathrm{C}$ & $6,39 \pm 0,35 B$ & $2,53 \pm 0,14 \mathrm{~A}$ & $6,45 \pm 0,54 \mathrm{C}$ & $81,56 \mathrm{~A}$ \\
\hline COZF65 & $13,88 \pm 0,34 \mathrm{C}$ & $3,41 \pm 0,02$ B & $5,14 \pm 0,56 \mathrm{C}$ & $3,01 \pm 0,80 \mathrm{~A}$ & $5,11 \pm 0,11 \mathrm{C}$ & $83,38 \mathrm{~A}$ \\
\hline
\end{tabular}

NOTA: (1) Os dados apresentados correspondem aos valores médios das análises das amostras feitas em triplicata. Médias seguidas por letras distintas nas colunas diferem entre si pelo teste de Tukey, com significância de $5 \%$ $(p \leq 0,05)$.

(2) $\mathrm{CRF}=$ pinhão fresco e cru; COZF = pinhão fresco cozido; CRF65 = farinha de pinhão cru desidratada a $65^{\circ} \mathrm{C} ; \mathrm{COZF} 65$ = farinha de pinhão cozido desidratada a $65^{\circ} \mathrm{C}$

$\left({ }^{\star}\right)$ Valores em base seca.

Em relação à umidade, a farinha COZF65 apresentou menor perda do que a CRF65 no período de secagem. Esse resultado pode estar relacionado ao fato de a água ser adsorvida na COZF65 por ligações fortes das pontes de hidrogênio pelas cadeias $\alpha$-D-glicose da amilose (hidrófilas) durante o período de cozimento e, assim, permanecerem estáveis (LEHNINGER, NELSON e COX, 2000).

A análise dos dados da Tabela 1 demonstra que os valores de umidade dos tratamentos CRF e COZF ficaram próximos, provavelmente pela manutenção da casca durante o cozimento, que limita a expansão da semente em volume. Variação nos teores de umidade também foi observada por CORDENUNSI et al. (2004) para as sementes de pinhão CRF 49,50\% e COZF 50,35\%.

Verificou-se menor perda nos teores de proteína da semente COZF quando comparada com a CRF, a qual pode estar relacionada às perdas por desnaturação e/ou por solubilização de pequenas moléculas proteicas durante o cozimento (LEHNINGER, NELSON e COX, 2000).

Análises efetuadas por OLIVEIRA, SANTOS e SCHEMIN (2007), em cascas de pinhão, resultaram em valores expressivos de cinzas $(2,14 \%)$ em base seca. Isto pode sugerir que ocorra migração de minerais da casca para a semente durante o cozimento de maneira a justificar o valor maior de cinzas no pinhão COZF (Tabela 1). Nos resultados obtidos no presente estudo, os teores de cinzas entre o pinhão CRF e COZF não apresentaram diferença significativa $(p>0,05)$.

O maior valor no teor de fibras da semente COZF $(16,88 \%)$ em relação a CRF $(15,34 \%)$ foi explicado por CORDENUNSI et al. (2004) em função da quantidade de fibras insolúveis e de amilose (cerca de 25\%) que contribuem para a formação de amido resistente após o resfriamento das sementes cozidas.

A diferença encontrada no teor de lipídios das sementes CRF e COZF, significativa ao nível de $5 \%(p \leq 0,05)$, pode ser consequência da oxidação por efeito térmico ou da migração de lipídios para a água de cozimento. A diminuição nos teores de lipídios e proteínas nas farinhas CRF65 e COZF65 são explicadas pelos efeitos da temperatura de secagem. As sementes são susceptíveis às mudanças físicas provocadas por gradientes de temperatura e umidade, durante o processo de obtenção das farinhas ocasionando expansão, contração e alterações na densidade e porosidade. Segundo CAMACHO et al. (2004), altas temperaturas podem causar danos nos tecidos vegetais devido à desintegração das membranas celulares por alterações nos lipídios que as constituem e na desnaturação de suas proteínas, lixiviação de eletrólitos e açúcares e produção de pigmentos carotenoides. A sensibilidade ao dano térmico depende da espécie, genótipo, teor de água, tempo de exposição e velocidade de secagem.

As farinhas, em geral, são os grãos moídos. Como as moagens reduzem o tamanho do endosperma também são responsáveis pela quebra das fibras existentes na semente, diminuindo seus teores na farinha. 
Ainda que a obtenção das farinhas de semente do pinhão tenha buscado a reprodução do procedimento industrial, algumas etapas foram adaptadas para a bancada de laboratório. Contudo, a secagem produziu perdas com diferenças significativas $(p \leq 0,05)$ na maioria dos constituintes determinados quando comparados os valores das sementes cozidas e cruas com suas respectivas farinhas.

As farinhas revelaram-se boa fonte de fibras (5,11\% para COZF65 e 6,45\% para CRF65), de proteínas (3,41\% para COZF65 e 3,07\% para CRF65) e lipídios (5,14\% para COZF65 e 6,39\% para $\mathrm{CRF} 65)$. As farinhas de pinhão também podem ser valorizadas se comparadas à farinha de trigo $(2,7 \%$ de fibras) e à farinha de milho (3,83\% de lipídios) (USDA, 2001).

Além das perdas nutricionais, as farinhas CRF65 e COZF65 apresentaram características físicas bem distintas no que diz respeito à coloração. A primeira assemelhou-se à farinha de trigo comum em relação à cor e à textura e a segunda apresentou cor amarelada e maior densidade pela incorporação de substâncias flavonoides da casca e adsorção de água. Fato já observado por CORDENUNSI et al., 2004.

\subsection{MICROSCOPIAELETRÔNICA DE VARREDURA}

A microscopia eletrônica de varredura tem sido utilizada na diferenciação de amidos, bem como para demonstrar os efeitos de tratamentos químicos e térmicos. Na Figura 1 estão representadas as estruturas dos grânulos das sementes da Araucaria angustifolia crua e cozida.

\section{FIGURA 1 - MICROSCOPIA ELETRÔNICA DE VARREDURA DOS GRÂNULOS DE AMIDO DAS SEMENTES CRUA E COZIDA DE Araucaria angustifolia}
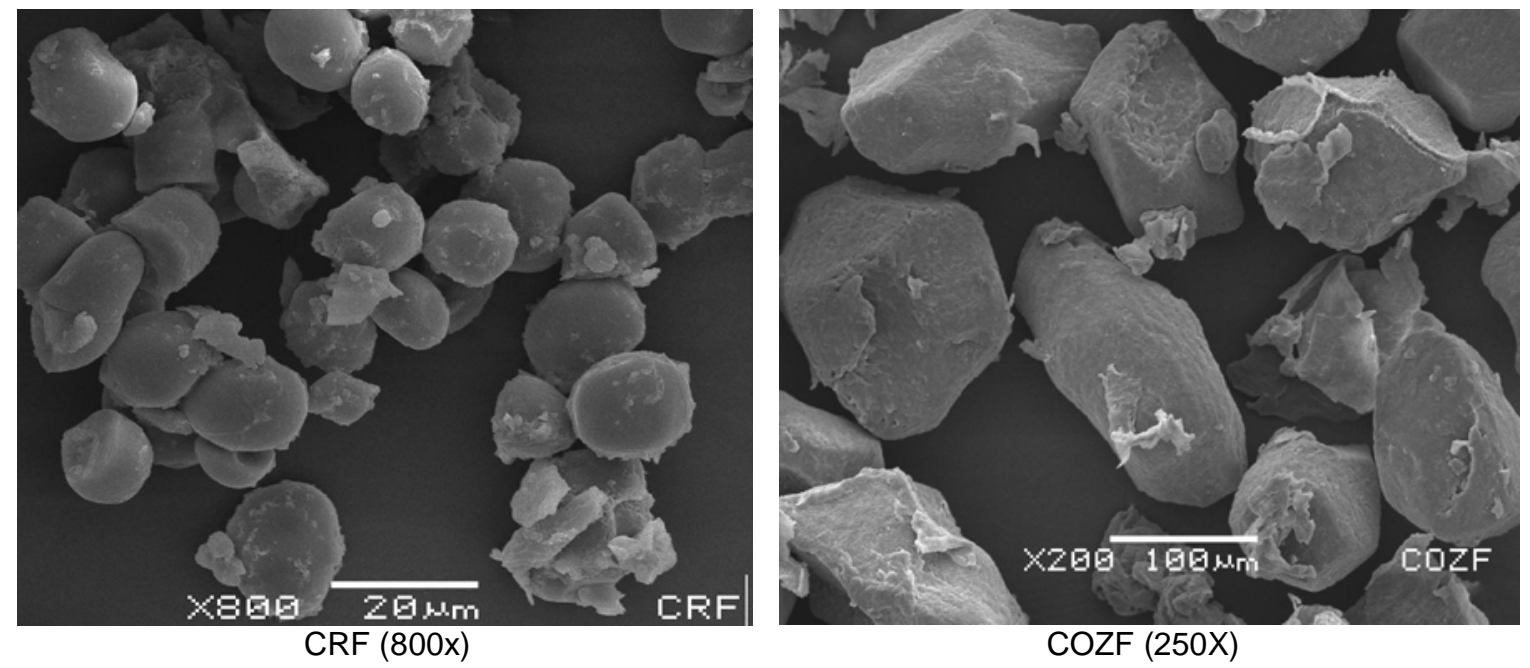

$\mathrm{CRF}=$ pinhão cru e fresco; $\mathrm{COZF}=$ pinhão cozido fresco.

Os grânulos da semente de pinhão CRF evideciaram morfologia similar ao amido da araruta (Maranta arundinacea) e amido de mandioca (Manihot esculenta), apresentando formato elipsoide com alguns côncavo-convexos característicos, mas diferindo nos diâmetros (entre 10 e $15 \mu \mathrm{m}$ ). Os grânulos da semente de pinhão COZF apresentaram morfologia poliédrica similar ao açafrão (Curcuma longa), embora seu diâmetro (entre 100 e $120 \mu \mathrm{m}$ ) seja dez vezes maior (ABAM, 2003).

Os diâmetros dos grânulos de amido das amostras das sementes cozidas mostraram-se maiores que os das cruas, face à adsorção das moléculas de água na estrutura do grânulo de amido da farinha durante a cocção. Tal fato foi confirmado por GAMA (2006). 

pinhão.

\section{FIGURA 2 - MICROSCOPIA ELETRÔNICA DE VARREDURA DOS GRÂNULOS DE AMIDO DAS FARINHAS DE PINHÃO}
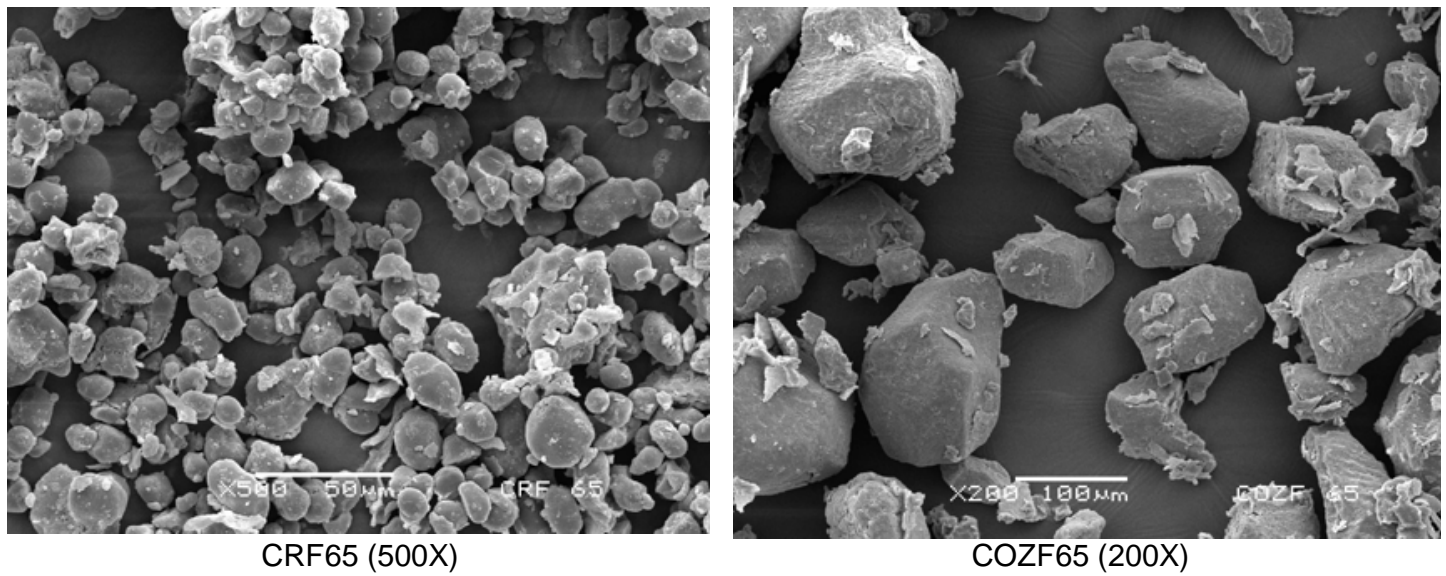

CRF65 = farinha de pinhão crua fresca; COZF65 = farinha de pinhão cozida fresca. 0 número 65 , ao lado dos termos CRF e COZ, significa a temperatura de secagem.

Neste trabalho foi possível visualizar as mudanças físicas e danos estruturais nos grânulos de amido nas sementes e farinhas de pinhão, que justificam a perda de nutrientes (proteínas e lipídios) por cocção, os efeitos físicos da moagem na redução do tamanho das partículas (e fibras) e da temperatura de secagem. Essas alterações foram mais evidenciadas na semente COZF pela maior visualização da fragmentação, como também na farinha COZF65.

\section{CONCLUSÃO}

O tratamento de cozimento alterou a composição centesimal das sementes de Araucaria angustifolia, com diferença significativa $(p<0,05)$ nos teores de lipídios e fibras.

As farinhas de pinhão, desidratadas a $65^{\circ} \mathrm{C}$, apresentaram perdas em todos os constituintes nutricionais, com diferença significativa apenas nos teores de proteínas e lipídios.

As maiores alterações de composição e de morfologia foram decorrentes do processamento das sementes para a obtenção de farinha nas etapas de cozimento e secagem. Contudo, as farinhas revelaram-se boas fontes de fibras, proteínas e lipídios.

O presente estudo demonstrou que a utilização das sementes da Araucaria angustolia na forma de farinha constitui boa opção tecnológica de aproveitamento da matéria-prima e como fonte nutricional para possíveis formulações de produtos alimentícios.

\section{ABSTRACT \\ Araucaria angustifolia SEEDS: MORPHOLOGICAL ASPECTS AND CHEMICAL COMPOSITION OF THE FLOUR}

Seeds of Araucaria angustifolia raw and cooked were subjected to air drying at $65^{\circ} \mathrm{C}$, and after, crushed as flour. Analysis of the centesimal composition was made of seeds and flours and of morphology by scanning electron microscopy (Jeol KAL 6360LV). The results showed that the cooked flour showed major changes from cooking, grinding and drying. The obtained flours are a good source of fibers (5.11\% for COZF65 and 
6.45\% for CRF65), protein (3.41\% for COZF65 and 3.07\% for CRF65) and lipids (5.14\% for COZF65 and $6.39 \%$ for CRF65). The flours present a technology option for the seeds of Araucaria angustifolia in the chemical and nutritional aspects.

Key-words: Araucaria angustifolia, DRYING; DEHYDRATION.

\section{REFERÊNCIAS}

1 ABAM. Associação Brasileira dos Produtores de Amido de Mandioca. Cultura de tuberosas amiláceas latino americanas. São Paulo: Fundação Cargill, 2003. v. 1.

2 AGROLINK. Portal do Conteúdo Agropecuário. Cereais de inverno: informações técnicas. Disponível em: <http:// www.agrolink.com.br>. Acesso em: 7 jul. 2007.

3 AOAC. Association of Official Analytical Chemists. Official methods of analysis of AOAC International. $17^{\text {th }}$ ed. Gaithersburg, 2000. v. 2.

4 BRASIL. Agência Nacional de Vigilância Sanitária. RDC n. 263, de 22 de setembro de 2005. Aprova o Regulamento técnico para produtos de cereais, amidos, farinhas e farelos. Diário Oficial [da] República Federativa do Brasil. Disponível em: http://e-legis.anvisa.gov.br/leisref/public/showAct.php?id=18822\&word=RDC Acesso em: 7 jul. 2007.

5 CAMACHO, D.G.; BARROS, A.C.S.A.; PESKE, S.T.; MENEZES, N.L. A secagem de sementes. Revista Ciência Rural, v. 34, n. 2, p. 603-608, 2004.

6 CLADERA-OLIVERA, F.; NORENA, C.Z.P.; WADA, K.; MARRCZAK, L.D.F. Alternativas tecnológicas do processamento e armazenamento do pinhão. In: SEMINÁRIO DO PROGRAMA DE PÓS GRADUAÇÃO EM ENGENHARIA QUÍMICA, OKTOBER FÓRUM, 2005, Porto Alegre. Anais... Porto Alegre: UFRGS, 2005.

7 CORDENUNSI, B.R.; MENEZES, E.W.; GENOVESE, M.I.; COLLI, C.; SOUZA, A. G.; LAJOLO, F. M. Chemical composition and glycemic index of Brazilian pine seeds (Araucaria angustifolia). Journal Agriculture Food Chemistry, v. 52, n.11, p. 3412-3416, 2004

8 FERNANDEZ, J. H. Identificação e caracterização de proteínas e genes expressos diferencialmente durante o desenvolvimento do embrião zigótico de Araucaria angustifolia. Campinas, 2003. 98 p. Tese (Doutorado em Biologia Celular e Estrutural) - Fundação de Amparo à Pesquisa de São Paulo, Universidade Estadual de Campinas.

9 FONSECA, S.C.L; FREIRE, H.B. Sementes recalcitrantes: problemas na pós pós-colheita. Bragantia Revista de Ciências Agronômicas, v.62, n.2, p.297-303, 2003.

10 GAMA, T.M.M.B. Estudos comparativos dos aspectos físico-químicos do pinhão nativo e do pinhão proveniente dos processos de polinização controlada de Araucária angustifolia e da influência do processo térmico. Curitiba, 2006. 98 p. Dissertação (Mestrado em Tecnologia de Alimentos) - Setor de Tecnologia, Universidade Federal do Paraná.

11 GREENFIELD, H.; SOUTHGATE, D.A.T. Food composition data: production, management and use. London: Chapman \& Hal, 1992. $243 \mathrm{p}$.

12 IAL. Instituto Adolfo Lutz. Normas analíticas do Instituto Adolfo Lutz: métodos químicos e físicos para análise de alimentos. 3 ed. São Paulo, 1985. v.1.

$13 \mathrm{KOCH}, \mathrm{Z}$; CORRÊA, M.C. Araucária: a floresta do Brasil meridional. Curitiba: Olhar Brasileiro, 2002. 148 p.

14 KOELLER, H.S. Estatística experimental. Curitiba: Universidade Federal do Paraná, 1999.

15 LEHNINGER, A.; NELSON, D.L.; COX, M.M. Principles of biochemistry. $3^{\text {rd }}$ ed. New York: Worth Publisher, 2000.

16 LIMA, N.N. Farinha de pinhão. Folha de Londrina. Folha Rural. Disponível em: <http://www.bonde.com.br>. Acesso em: 30 jun. 2006.

17 MICROSOFT CORPORATION. Microsoft Office Excel: windows 2000/XP/2003. Washington, 2003.

18 NEVES, C.S.V.J. Sementes recalcitrantes: revisão de literatura. Revista Pesquisa Agropecuária Brasileira, Brasília, v. 29, n. 9, p.1459-1467, set. 1994.

19 OLIVEIRA, K.P.; SANTOS, M.S.; SCHEMIN, M.H.C. Caracterização físico-química da semente e resíduos da Araucaria angustifolia. In: SEMANA DE TECNOLOGIA DE ALIMENTOS, 5., 2007, Ponta Grossa. Anais... Ponta Grossa: UTFP, 2007. 
20 PARK, K.J.; YADO, M.K.M.; BROD, F.P.R. Estudo de secagem de pêra Bartlett (Pyrus $s p$ ) em fatias. Ciência e Tecnologia de Alimentos, Campinas, v. 21, n. 3, p. 288-292, set/dez. 2001.

21 SBRT. Sistema Brasileiro de Respostas Técnicas. Desidratação de frutas, 2005. Disponível em: <http:// www.sbrt.ibict.br>. Acesso em: 12 mar. 2007.

22 USDA. United States Department of Agriculture. Nutrient database for standard reference. Maryland, 2001. 